\title{
The protective effects of lafutidine for bortezomib induced peripheral neuropathy
}

This article was published in the following Dove Press journal: Journal of Blood Medicine

10 July 2013

Number of times this article has been viewed

\section{Machiko Tsukaguchi \\ Masaru Shibano \\ Ai Matsuura \\ Satoru Mukai}

Department of Hematology,

Sakai City Hospital, Osaka, Japan
Correspondence: Machiko Tsukaguchi Department of Hematology, Sakai City Hospital, I-I-I, Minamiyasui-cho, Sakai City, Osaka, Japan, 590-0064

$\mathrm{Tel}+8172221 \quad 1700$

Fax +8I 7222533 I2

Email tsukaguchi-m@sakai-hospital.jp or kugiya@leto.eonet.ne.jp

\begin{abstract}
Peripheral neuropathy $(\mathrm{PN})$ caused by bortezomib is an important complication of multiple myeloma. Subcutaneous injection of bortezomib reduced PN, but $24 \%$ of cases were grade $2 \mathrm{PN}$ and $6 \%$ of cases were grade $3 \mathrm{PN}$. PN higher than grade 2 was not resolved by subcutaneous injection. PN higher than grade 3 has serious dose limiting toxicity and is the cause of discontinuing bortezomib treatment. Lafutidine is an H2-blocker with gastroprotective activity and is thought to function by increasing mucosal blood flow via capsaicin sensitive neurons. The same activity of lafutidine is considered to improve glossodynia and taxane induced PN. We hypothesized that lafutidine prevents or improves PN that is caused by bortezomib. In the current study, bortezomib was administered in the usual manner (intravenous administration of bortezomib $1.3 \mathrm{mg} / \mathrm{m}^{2}$, twice a week for 2 weeks, followed by 1 week without treatment) for up to four cycles to compare our data with other studies. Lafutidine was administered orally at a dose of $10 \mathrm{mg}$ twice daily. In our eight evaluated cases, the total occurrence of PN was four out of eight patients (50\%). There were only grade $1 \mathrm{PN}$ (4 out of 8) cases, and no cases higher than grade 2 . We conclude that (1) the total occurrence of PN was not improved, (2) there was no PN after the first course, (3) there were only grade 1 cases and there were no cases higher than grade 2, and (4) no cases discontinued bortezomib treatment because of PN. This is the first report showing that lafutidine is useful for the amelioration of bortezomib induced PN.
\end{abstract}

Keywords: bortezomib induced peripheral neuropathy, lafutidine, capsaicin sensitive neurons, calcitonin gene-related peptide, transient receptor potential 1, multiple myeloma

\section{Introduction}

Bortezomib is an important drug for treatment of multiple myeloma (MM). ${ }^{1-3}$ However, peripheral neuropathy $(\mathrm{PN})$ is a troublesome adverse event caused by bortezomib. ${ }^{4,5} \mathrm{PN}$ is the cause of reducing the dose or discontinuing bortezomib treatment. ${ }^{2,4}$ Subcutaneous injection of bortezomib reduces PN, however, PN grade $2(24 \%)$ and grade $3(6 \%)$ were still reported. ${ }^{6} \mathrm{PN}$ higher than grade 3 is not resolved by subcutaneous injection of bortezomib. ${ }^{6}$ There are some reviews of bortezomib induced peripheral neuropathy (BIPN). ${ }^{7,8}$ The pathogenesis of BIPN is thought to be as follows: (1) mitochondrial and endoplasmic reticulum damage appears to be one of the causes of BIPN; (2) bortezomib activates the mitochondrial based apoptotic pathway; ${ }^{9}(3)$ inhibition of nuclear factor kappa $\mathrm{B}$ activation, which is the main action of bortezomib, ${ }^{10}$ blocks the transcription of nerve growth factor mediated neuronal survival; ${ }^{11}$ (4) intramitochondrial calcium concentrations are increased by bortezomib leading to disruption of calcium homeostasis and induction of mitochondrial apoptosis; ${ }^{12}$ and (5) proteasome inhibitor induced PN may also affect microtubule associated proteins and cause microtubule stabilization. ${ }^{13}$ 
Lafutidine is an H2-receptor antagonist with gastroprotective activity and is thought to function via capsaicin sensitive afferent neurons. ${ }^{14-17}$ Capsaicin has gastroprotective activity by increasing mucosal blood flow via capsaicin sensitive afferent neurons. ${ }^{18,19}$ The terminals of capsaicin sensitive sensory neurons and their dorsal root ganglia contain transient receptor potential 1 (TRPV1) that is thought to be the receptor for capsaicin. ${ }^{20}$ TRPV1, activated by capsaicin, releases calcitonin gene-related peptide (CGRP) ${ }^{20}$ which is the major vasodilator released from capsaicin sensitive nerves. ${ }^{21}$ Capsaicin and CGRP lose their gastroprotective activity by blockade of the nitric oxide system. ${ }^{18,21}$ Moreover, capsaicin is thought to selectively block afferent sensory neurons. ${ }^{22}$

Lafutidine is thought to increase gastric mucosal blood flow by the mechanisms of activation of capsaicin sensitive afferent nerves and nitric oxide. ${ }^{14}$ Lafutidine appears to function similarly to capsaicin via the same neurons. ${ }^{15-17}$ Lafutidine has been reported to improve glossodynia ${ }^{20,23}$ and taxane induced PN. ${ }^{24}$ In these reports, it was assumed that the same activity via capsaicin sensitive afferent nerves improves glossodynia and taxane induced PN. We hypothesized that lafutidine prevents or improves PN that is caused by bortezomib. Therefore, we performed a clinical pilot study on bortezomib and lafutidine in patients with MM.

\section{Patients and methods}

Fourteen cases of MM treated with bortezomib and dexamethasone therapy (BD) from November 2010 to January 2012 were included in this pilot study. Table 1 shows the patient characteristics. Five newly diagnosed patients received intravenous high dose dexamethasone therapy ${ }^{25}$ before BD. Nine patients were refractory or relapsed cases. Four patients had a vertebral compression fracture, two patients had a rib fracture, and two patients had plasmacytoma of the bones at the beginning of $\mathrm{BD}$. Bortezomib was administered in the usual manner (intravenous administration of bortezomib $1.3 \mathrm{mg} / \mathrm{m}^{2}$, twice a week for 2 weeks, followed by 1 week without treatment) for up to four cycles. Dexamethasone was administered using a modified method, by infusing intravenously at a dose of $33 \mathrm{mg} /$ patient simultaneously with bortezomib. PN was evaluated at the beginning of every course, from the first course to the end of the fourth course. At this time, lafutidine was administered orally at a dose of $10 \mathrm{mg}$ twice a day throughout the study period with written informed consent under the permission of the Institutional Review Board (of Sakai City Hospital). After four courses, bortezomib was continued, but not administered in the usual manner. Intravenous administration, twice a week, for a period of 2 weeks, was too difficult to continue for elderly patients because of the frequency of therapy, general fatigue

Table I Patient characteristics and results $(n=14)$

\begin{tabular}{|c|c|c|c|c|c|c|}
\hline Case no & Age/sex & Type of MM & States at the start of BD & Previous therapy & PN (grade) & Results \\
\hline I & $68 / M$ & $\lg G \kappa$ & Vertebral compression fracture & MP/DMVM & 0 & Completed 4 courses without skipping \\
\hline 2 & $5 I / M$ & $\lg A \kappa$ & Vertebral compression fracture & HDD & 1 & $\begin{array}{l}\text { Finished } 4 \text { courses with long-term } \\
\text { skipping }\end{array}$ \\
\hline 3 & 77/M & $\lg G \kappa$ & Nothing particular & $\mathrm{RT} / \mathrm{BIS} / \mathrm{DEXA}$ & 0 & Completed 4 courses without skipping \\
\hline 4 & $60 / F$ & $\lambda \mathrm{BJP}$ & Anemia & VAD/MP & 0 & Completed 4 courses without skipping \\
\hline 5 & $66 / M$ & $\kappa \mathrm{BJP}$ & Diabetic nephropathy & HDD & - & $\begin{array}{l}\text { Dropped out within } 2 \text { courses } \\
\text { because of disqualification }\end{array}$ \\
\hline 6 & $75 / F$ & $\lg G \kappa$ & Vertebral compression fracture & DMVM/IFN/MP & 1 & Finished 4 courses with skipping \\
\hline 7 & $59 / F$ & $\lg G \lambda$ & Nothing particular & HDD & 1 & Completed 4 courses without skipping \\
\hline 8 & $80 / F$ & $\lg A \kappa$ & Vertebral compression fracture & DMVM & - & $\begin{array}{l}\text { Dropped out within } 2 \text { courses because } \\
\text { of general fatigue and diarrhea }\end{array}$ \\
\hline 9 & $6 \mathrm{I} / \mathrm{F}$ & $\lg G \kappa$ & Rib fracture & HDD & 1 & $\begin{array}{l}\text { Completed } 4 \text { courses without } \\
\text { skipping but with reduced dose }\end{array}$ \\
\hline 10 & $64 / F$ & $\lg D \lambda$ & Diabetic nephropathy & HDD & - & $\begin{array}{l}\text { Dropped out for leukemic change } \\
\text { after } 2 \text { courses }\end{array}$ \\
\hline 11 & $63 / M$ & $\lg G \kappa$ & Rib fracture & DMVM & - & $\begin{array}{l}\text { Dropped out within } 2 \text { courses } \\
\text { because of general fatigue }\end{array}$ \\
\hline 12 & $73 / F$ & $\lg A \kappa$ & Nothing particular & DMVM & - & $\begin{array}{l}\text { Dropped out within } 2 \text { courses } \\
\text { because of general fatigue }\end{array}$ \\
\hline 13 & $75 / F$ & $\lg A \kappa$ & Plasmacytoma of bone & MP & 0 & Completed 4 courses without skipping \\
\hline 14 & $78 / M$ & $\lg G \kappa$ & Plasmacytoma of bone & $\mathrm{DMVM} / \mathrm{MP}$ & - & $\begin{array}{l}\text { Dropped out within } 2 \text { courses because } \\
\text { of general fatigue and diarrhea }\end{array}$ \\
\hline
\end{tabular}

Abbreviations: BD, bortezomib/dexamethasone; BIS, bisphosphonate; BJP, Bence-Jones protein; DEXA, dexamethasone; DMVM, dexamethasone/melphalan/vincristine/ ranimustine; F, female; HDD, high dose dexamethasone; IFN, interferon; Ig, immunoglobulin; M, male; MM, multiple myeloma; MP, melphalan/prednisolone; PN, peripheral neuropathy; RT, radiation therapy; VAD, vincristine/doxorubicin/dexamethasone. 
and/or diarrhea. Moreover, Richardson et al reported a dose modification guideline of bortezomib, ${ }^{5}$ and we adopted intravenous administration of bortezomib once a week or less after four courses.

At the beginning of every course, PN was evaluated by the Short Form McGill Pain Questionnaire, ${ }^{27}$ the Patient Neurotoxicity Questionnaire, ${ }^{28}$ the visual analog scale, and the National Cancer Institute's Common Terminology Criteria for Adverse Events version 3. Statistical analyses were performed with Fisher's exact test using JMP version 10.0 (SAS Institute Inc., Cary, NC, USA).

\section{Results}

All 14 cases received the first course of bortezomib. PN was not observed after the first course. Six cases dropped out before the third course, not because of PN, but because of progression of the disease, disqualification, general fatigue, or diarrhea. No cases discontinued bortezomib therapy because of PN. Six patients completed four courses of bortezomib without missing any treatment. Among these patients, two of the six patients (33\%) developed PN grade 1. The other four patients did not develop PN. Including those patients who missed treatment with or without a reduction in dose, eight patients finished four courses of bortezomib. We evaluated these eight cases. PN developed in four of the eight patients (50\%). However, all PN cases were grade 1 and there were no severe cases. PN higher than grade 2 was not observed in this study (Table 1).

\section{Discussion}

In our pilot study, PN was not observed after the first course. However, in a Japanese Phase I/II study, at least $14.71 \%$ of patients had PN after the first course. ${ }^{26}$ In another Japanese report, at least $20 \%$ of patients had $\mathrm{PN}$ after the first course. ${ }^{29}$ Therefore, lafutidine may prevent PN, at least until the end of the first course.
In our study, six of 14 cases $(43 \%)$ dropped out of bortezomib treatment before the third cycle. However, in the Study of Uncontrolled Myeloma Management (SUMMIT) trial, ${ }^{1} 54$ of 202 cases (27\%) discontinued treatment early because of progressive disease and 45 of 202 cases (22\%) did so because of adverse events. Therefore, 99 of 202 cases (49\%) dropped out of treatment early in the SUMMIT trial. The high dropout rate seems to be common to bortezomib treatment.

PN was evaluated until the end of the fourth course because the onset of PN in a previous Japanese trial was $47 \%$, with a median time of 79 days (almost four courses). ${ }^{26}$ In another Japanese report, PN was observed within two courses,${ }^{29}$ and a median time of five courses, ${ }^{30}$ and three courses $^{31}$ have been reported. Because our study had no control group, it was important to compare the occurrence of $\mathrm{PN}$ with something else. Therefore, $\mathrm{PN}$ after four courses was evaluated under similar conditions to compare our results with previous studies. We thought that it was necessary to complete four courses to compare our results with those from other studies.

The effects of lafutidine on PN were observed in eight patients who finished four courses with or without missing treatment. The occurrence of PN in this study was compared with that in other reports as follows and is summarized in Table 2. The total occurrence of PN in this study was 50\%. It was $47 \%$ in a Japanese Phase I/II study, ${ }^{26} \geq 40 \%$ in a study from Kyushu University, ${ }^{29}$ and $\geq 87 \%$ in a study from the Niigata Cancer Center. ${ }^{30}$ The total occurrence of PN was not improved in our study. However, in our study, all the cases were grade 1 and there were no severe cases.

PN higher than grade 3 was not observed in the current study. The percentage of PN higher than grade 3 was $3 \%$ in the Japanese Phase I/II study, $13 \%$ in the study from Kyushu University, $6.7 \%$ in the study from Niigata Cancer

Table 2 Comparison of the current study with previous reports

\begin{tabular}{|c|c|c|c|c|c|}
\hline \multirow[t]{2}{*}{ Reports } & \multicolumn{5}{|l|}{ Number (\%) } \\
\hline & Total occurrence of PN & Grade I & Grade 2 & Higher than grade 2 & Higher than grade 3 \\
\hline This trial $(n=8)$ & $4(50)$ & $4(50)$ & 0 & 0 & 0 \\
\hline Japanese Phase $1 / I I$ study ${ }^{26}(n=34)$ & $16(47)$ & - & - & - & I (3) \\
\hline Kyushu University Hospita ${ }^{29}(n=15)$ & $\geq 6(\geq 40)$ & - & - & - & $2(13)$ \\
\hline Niigata Cancer Center ${ }^{30}(n=60)$ & $\geq 52(\geq 87)$ & - & - & - & $4(6.7)$ \\
\hline Six institutes in Kyoto and Osaka ${ }^{31}(n=88)$ & $51(58)$ & & & & $22(25)$ \\
\hline \multicolumn{6}{|l|}{ For reference } \\
\hline $\operatorname{VISTA}^{3}(n=340)$ & $159(47)$ & $(15)$ & (19) & - & $45(13)$ \\
\hline $\operatorname{APEX}^{5}(n=331)$ & $124(37)$ & $(10)$ & $(18)$ & - & $30(9)$ \\
\hline Moreau et $\mathrm{al}^{6}(\mathrm{n}=74)$ & $33(44)$ & - & $21(28)$ & $30(40.1)^{*}$ & $9(12.1)$ \\
\hline
\end{tabular}

Note: $* P=0.0242$.

Abbreviations: PN, peripheral neuropathy; VISTA, Velcade as Initial Standard Therapy in multiple myeloma Assessment with melphalan and prednisone; APEX, Assessment of Proteasome inhibition for Extending remissions. 
Center, and $25 \%$ in the study from six institutes in Kyoto and Osaka. ${ }^{31}$

Subcutaneous injection of bortezomib reduced BIPN, however, it was still reported that there were cases of BIPN grade 2 or worse $(24 \%)$ and grade 3 or worse $(6 \%){ }^{6} \mathrm{PN}$ higher than grade 3 was not resolved by subcutaneous injection of bortezomib. ${ }^{6} \mathrm{PN}$ higher than grade 3 is thought to have serious dose limiting toxicity and is the cause of discontinuing bortezomib treatment.

Some studies have reported that discontinuation of bortezomib treatment was required because of BIPN., ${ }^{4,5,29}$ With regard to discontinuing treatment, in the Phase III Assessment of Proteasome inhibition for Extending remissions (APEX) study, it was reported that 31 of 331 patients (9\%) had to discontinue bortezomib treatment because of BIPN, and 14 of 331 (4\%) patients who discontinued treatment because of PN higher than grade 2 did so within the first three cycles. ${ }^{5}$ When comparing the discontinuation of bortezomib therapy because of BIPN within the first three cycles, which was a similar short-term observation between studies, in our study, the rate of discontinuation of bortezomib was $0 \%$ and in the Phase III APEX trial it was 4\%.

Moreau et al reported that PN higher than grade 2 occurred in 30 of 74 patients $(40.1 \%)$ in the group receiving intravenous bortezomib at a cumulative dose of $20.8 \mathrm{mg} / \mathrm{m}^{2}$, which is consistent with four complete treatment cycles. ${ }^{6}$ The cohort in our study was too small for statistical analysis, but between the study by Moreau et al and ours, a significant statistical difference $(P=0.0242)$ was suspected. Moreover, in a study from Kyushu University, ${ }^{29}$ two out of ten patients required discontinuation of bortezomib treatment because of BIPN within two courses. Our results suggested that PN higher than grade 3 was prevented by lafutidine treatment, and no patients discontinued treatment because of PN. We concluded that PN was mild in all patients, with no severe cases.

We speculate that lafutidine protected the progress of severe PN. The reason why lafutidine prevents severe PN is unknown. Lafutidine increases gastric mucosal blood flow by the mechanisms of capsaicin sensitive afferent nerves and nitric oxide. ${ }^{14}$ Capsaicin has been reported to increase local blood flow ${ }^{18,19}$ and to selectively block afferent sensory neurons via capsaicin sensitive afferent neurons. ${ }^{22}$ Lafutidine appears to function in a similar manner to capsaicin via the same neurons. ${ }^{15-17}$ There are some reports that lafutidine improves glossodynia ${ }^{20,23}$ and taxane induced PN. ${ }^{24}$ In these reports, it was assumed that lafutidine works in a similar manner to capsaicin via capsaicin sensitive afferent neurons and lafutidine increases local blood flow. We believe that the same activity of lafutidine via capsaicin sensitive afferent neurons protected against the progress of severe $\mathrm{PN}$ in our patients.

In the above mentioned reports, ${ }^{20,23,24}$ lafutidine was administered after developing PN and it improved PN, whereas in our study, it was administered before PN and was thought to protect against the progression of severe PN. The discrepancy between these previous studies and our study appears to depend on the timing of administration of lafutidine. In either case, whether lafutidine was administered before or after developing PN, lafutidine was effective for PN. There were no adverse events of lafutidine treatment in the current study. We conclude that lafutidine is a useful drug for treating BIPN and speculate activity via capsaicin sensitive neurons leads to improvement or reduction of neurotoxicity. However, this result is only from a pilot study. Further studies are required to determine the effects of lafutidine on PN.

\section{Acknowledgments}

The authors thank Dr Misako Kaidou for helpful suggestions for determining PN. The authors thank Dr Iwao Gohma for helpful suggestions.

\section{Disclosure}

The authors declare no conflicts of interest in this work.

\section{References}

1. Richardson PG, Barlogie B, Berenson J, et al. A phase 2 study of bortezomib in relapsed, refractory myeloma. $N$ Engl J Med. 2003;348(26): 2609-2617.

2. Richardson PG, Sonneveld P, Schuster MW, et al. Bortezomib or highdose dexamethasone for relapsed multiple myeloma. $N$ Engl J Med. 2005;352(24):2487-2498.

3. San Miguel JF, Schlag R, Khuageva NK, et al. Bortezomib plus melphalan and prednisone for initial treatment of multiple myeloma. N Engl J Med. 2008;359(9):906-917.

4. Dimopoulos MA, Mateos MV, Richardson PG, et al. Risk factors for, and reversibility of, peripheral neuropathy associated with bortezomibmelphalan-prednisone in newly diagnosed patients with multiple myeloma: subanalysis of the phase 3 VISTA study. Eur J Haematol. 2011;86(1):23-31.

5. Richardson PG, Sonneveld P, Schuster MW, et al. Reversibility of symptomatic peripheral neuropathy with bortezomib in the phase III APEX trial in relapsed multiple myeloma: impact of a dose-modification guideline. Br J Haematol. 2009;144(6):895-903.

6. Moreau P, Pylypenko H, Grosicki S, et al. Subcutaneous versus intravenous administration of bortezomib in patients with relapsed multiple myeloma: a randomised, phase 3, non-inferiority study. Lancet Oncol. 2011;12(5):431-440.

7. Argyriou AA, Iconomou G, Kalofonos HP. Bortezomib-induced peripheral neuropathy in multiple myeloma: a comprehensive review of the literature. Blood. 2008;112(5):1593-1599.

8. Richardson PG, Delforge M, Beksac M, et al. Management of treatmentemergent peripheral neuropathy in multiple myeloma. Leukemia. 2012;26(4):595-608. 
9. Cavaletti G, Gilardini A, Canta A, et al. Bortezomib-induced peripheral neurotoxicity: a neurophysiological and pathological study in the rat. Exp Neurol. 2007;204(1):317-325.

10. Hideshima T, Chauhan D, Richardson P, et al. NF-kappa B as a therapeutic target in multiple myeloma. J Biol Chem. 2002;277(19): 16639-16647.

11. Heese K, Inoue N, Sawada T. NF-kappaB regulates B-cell-derived nerve growth factor expression. Cell Mol Immunol. 2006;3(1):63-66.

12. Landowski TH, Megli CJ, Nullmeyer KD, Lynch RM, Dorr RT. Mitochondrial-mediated disregulation of $\mathrm{Ca} 2+$ is a critical determinant of Velcade (PS-341/bortezomib) cytotoxicity in myeloma cell lines. Cancer Res. 2005;65(9):3828-3836.

13. Poruchynsky MS, Sackett DL, Robey RW, Ward Y, Annunziata C, Fojo T. Proteasome inhibitors increase tubulin polymerization and stabilization in tissue culture cells: a possible mechanism contributing to peripheral neuropathy and cellular toxicity following proteasome inhibition. Cell Cycle. 2008;7(7):940-949.

14. Shibata $\mathrm{M}$, Onodera $\mathrm{S}$, Inaba $\mathrm{N}$, et al. Capsaicin sensitive afferent nerves in the mechanisms of gastroprotective and antiulcer effects of lafutidine, a novel antiulcer drug. Ulcer Research. 1997;24(1):33-37.

15. Onodera S, Shibata M, Tanaka M, Inaba N, Yamaura T, Ohnishi H. Gastroprotective activity of FRG-8813, a novel histamine H2-receptor antagonist, in rats. Jpn J Pharmacol. 1995;68(2):161-173.

16. Yamamoto H, Horie S, Uchida M, Tsuchiya S, Murayama T, Watanabe K. Effects of vanilloid receptor agonists and antagonists on gastric antral ulcers in rats. Eur J Pharmacol. 2001;432(2-3):203-210.

17. Umeda M, Fujita A, Nishiwaki H, Takeuchi K. Effect of lafutidine, a novel histamine $\mathrm{H} 2$-receptor antagonist, on monochloramine-induced gastric lesions in rats: role of capsaicin-sensitive sensory neurons J Gastroenterol Hepatol. 1999;14(9):859-865.

18. Holzer P. Neural emergency system in the stomach. Gastroenterology. 1998;114(4):823-839.

19. Holzer P, Pabst MA, Lippe IT, et al. Afferent nerve-mediated protection against deep mucosal damage in the rat stomach. Gastroenterology. 1990;98(4):838-848.

20. Tachibana T, Chiba H. Relationship between glossodynia and capsaicin sensitive sensory neurons-Examination of circulatory dynamics and immunohistochemistry. J Jpn Stomatol Soc. 2006;55(3):167-178. Japanese.
21. Lambrecht N, Burchert M, Respondek M, Muller KM, Peskar BM. Role of calcitonin gene-related peptide and nitric oxide in the gastroprotective effect of capsaicin in the rat. Gastroenterology. 1993;104(5): 1371-1380.

22. Holzer P. Capsaicin: cellular targets, mechanisms of action, and selectivity for thin sensory neurons. Pharmacol Rev. 1991;43(2):143-201.

23. Tachibana T, Suzuki M, Takamori M, Ino T, Aoki M, Chiba H. Comparative study of effect by lafutidine and clotiazepam on patients with glossodynia. J Jpn Stomatol Soc. 2003;52(4):188-194. Japanese.

24. Nagano H, Sanai H, Muraoka M, Takagi K. Efficacy of lafutidine, a histamine H2-receptor antagonist, for taxane-induced peripheral neuropathy in patients with gynecological malignancies. Gynecol Oncol. 2012;127(1):172-174.

25. Alexanian R, Dimopoulos MA, Delasalle K, Barlogie B. Primary dexamethasone treatment of multiple myeloma. Blood. 1992;80(4): $887-890$.

26. Ogawa Y, Tobinai K, Ogura M, et al. Phase I and II pharmacokinetic and pharmacodynamic study of the proteasome inhibitor bortezomib in Japanese patients with relapsed or refractory multiple myeloma. Cancer Sci. 2008;99(1):140-144.

27. Yamaguchi M, Kumano H, Yamauchi Y, Kadota Y, Iseki M. The development of a Japanese version of the Short-Form McGill Pain Questionnaire. J Japan Society Pain Clinicians. 2007;14:9-14.

28. Hausheer FH, Schilsky RL, Bain S, Berghorn EJ, Lieberman F. Diagnosis, management, and evaluation of chemotherapy-induced peripheral neuropathy. Semin Oncol. 2006;33(1):15-49.

29. Makieda D, Hisaeda S, Kinoshita H, et al. Investigation of adverse drug reactions in bortezomib therapy for relapsed multiple myeloma. Jpn J Pharm Health Care Sci. 2010;36(4):270-276.

30. Igarashi N, Chou T, Hirose T, Imai Y, Ishiguro T. Bortezomib and dexamethasone for Japanese patients with relapsed and refractory multiple myeloma: a single center experience. Int J Hematol. 2010;92(3): 518-523.

31. Kobayashi T, Kuroda J, Shimura K, et al. Bortezomib plus dexamethasone for relapsed or treatment refractory multiple myeloma: the collaborative study at six institutes in Kyoto and Osaka. Int J Hematol. 2010;92(4):579-586.
Journal of Blood Medicine

\section{Publish your work in this journal}

The Journal of Blood Medicine is an international, peer-reviewed, open access, online journal publishing laboratory, experimental and clinical aspects of all topics pertaining to blood based medicine including but not limited to: Transfusion Medicine; Blood collection, Donor issues, Transmittable diseases, and Blood banking logistics; Immunohematology; Artificial and alternative

\section{Dovepress}

blood based therapeutics; Hematology; Biotechnology/nanotechnology of blood related medicine; Legal aspects of blood medicine; Historical perspectives. The manuscript management system is completely online and includes a very quick and fair peer-review system. Visit http://www.dovepress.com/ testimonials.php to read real quotes from published authors. 